UC-13

\title{
Bond-Strength Studies for 1-Mil-Diameter Gold Wires Bonded to Hybrid Microcircuit Substrates
}

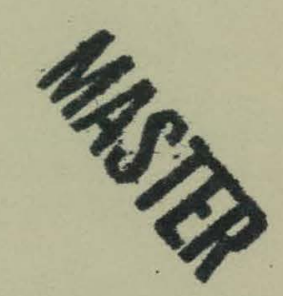

Y. R. Kan, V. C. Prantil

Prepared by Sandia National Laboratories, Albuquerque, New

Mexico 87185 and Livermore, California 94550 for the United

States Department of Energy under Contract DE-AC04-76DP00789.

Printed December 1981

\section{Sandia National Laboratories}




\section{DISCLAIMER}

This report was prepared as an account of work sponsored by an agency of the United States Government. Neither the United States Government nor any agency Thereof, nor any of their employees, makes any warranty, express or implied, or assumes any legal liability or responsibility for the accuracy, completeness, or usefulness of any information, apparatus, product, or process disclosed, or represents that its use would not infringe privately owned rights. Reference herein to any specific commercial product, process, or service by trade name, trademark, manufacturer, or otherwise does not necessarily constitute or imply its endorsement, recommendation, or favoring by the United States Government or any agency thereof. The views and opinions of authors expressed herein do not necessarily state or reflect those of the United States Government or any agency thereof. 


\section{DISCLAIMER}

Portions of this document may be illegible in electronic image products. Images are produced from the best available original document. 
Issued by Sandia Laboratories, operated for the United States Department of Energy by Sandia Corporation.

\section{NOTICE}

This report was prepared as an account of work sponsored by the United States Government. Neither the United States nor the United States Department of Energy, nor any of their employees, nor any of their contractors, subcontractors, or their employees, makes any warranty, express or implied, or assumes any legal liability or responsibility for the accuracy, completeness or usefulness of any information, apparatus, product or process disclosed, or represents that its use would not infringe privately owned rights. 


\section{PAGES 1 to 2 WERE INTENTIONALLY LEFT BLANK}




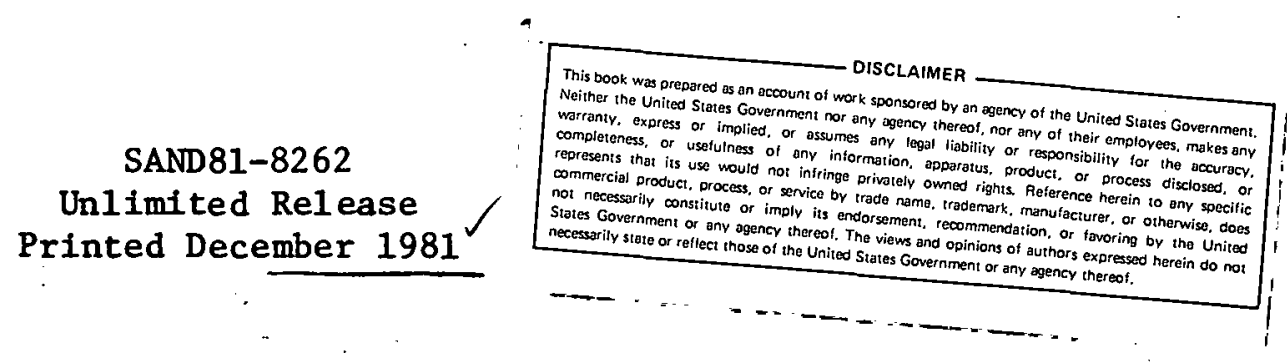

BOND-STRENGTH STUDIES FOR 1-MIL-DIAMETER

GOLD WIRES BONDED. TO HYBRID MICROCIRCUIT SUBSTRATES

Y. R. Kan and V. C. Prantil

Analytical Mechanics Division Sandia National Laboratories, Livermore

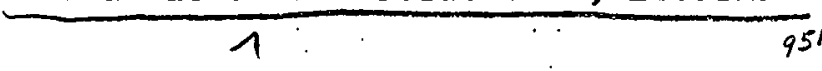

\author{
$12^{38}$
}

ABSTRACT

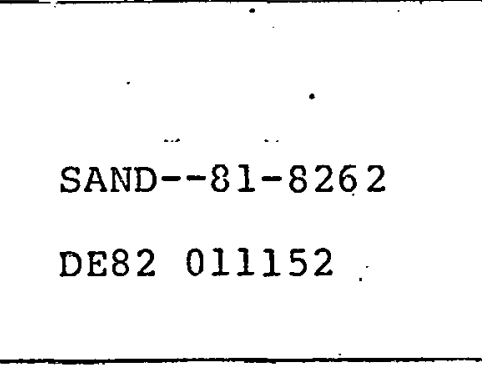

\begin{abstract}
Finite-element calculations were performed for the inertial loading on a onemil diameter gold wire with a 70-mil span subjected to the W79 artillery she11 environments. The calculated forces exerted on the ball bond and wedge bond resulting from the inertial loads on the wire are 0.17 grams and 0.2 grams, respectively.
\end{abstract}

Preliminary statistical analyses of the bond strength data obtained from the conventional loop-hook pull tests for a multiplexer substrate HMC ( $P / N 239234$, $\mathrm{S} / \mathrm{N}$ 1022) have shown that the ball bond is strong enough to withstand the 0.17 gram design limit load due to the W79 gun barrel environments with a very low probability of failure.

For the wedge bond, however, the results of a statistical analysis for the bond strength using loop-hook pull test data and a Gaussian distribution indicate that the probability of failure (.78\%) at 0.2 gram design limit load may be high enough to cause a problem. This is consistent with the experience obtained by Bendix that the wedge bonds are generally much weaker than ball bonds in multiplexer substrates.

Instead of a loop-hook pull test, a fixed-angle pull test, which closely simulates the actual loading condition from the artillery shell environments, was proposed and used to better evaluate the strengths and statistical characteristics of the wedge bonds. The fixed angle pull test was performed on one group of virgin wedge bonds on a multiplexer substrate HMC (S/N 1023) and on another group of wedge bonds on a similar multiplexer substrate which had undergone post assembly testing. The measured wedge bond strength data, using fixed-angle pull tests, were analyzed using the non-symmetrical Weibull statistical distribution theory. The results predicted the wedge bonds from both groups have probabilities of fallure much lower than originally estimated using the conventional loop-hook pull test data. The probabilities of failure at and below 0.2 gram design limit load are $6.5 \times 10^{-6 \%}$ for a virgin wedge bond and $7.6 \times 10^{-4 \%}$ for the post assembly tested wedge bond. The 
original estimated probability of fallure, using a Weibull distribution and the conventional loop-hook pull test bond strength data provided by Bendix, is $2.1 \times 10^{-2} \%$. The major advantage of the Weibull distribution theory over the normal Gaussian distribution theory is that the Weibull distribution is bounded on one side and can simulate zero accumulated distribution function at zero bond strength. But a normal Gaussian distribution always has a certain probability density function at zero and below zero (negative bond strength). The predicted negative bond strength is physically unrealistic.

The degradation of the wedge bond strength due to post assembly testing is significant as indicated by the large increase in probability of failure (from $6.5 \times 10^{-6 \%}$ to $7.6 \times 10^{-4 \%}$ ) for the post assembly tested wedge bonds. To illustrate this, consider a worst case example which assumes all wires bonded to the hybrid microcircuit substrates have the same geometry and loading conditions as shown in Figures 1 and 3 , respectively. Assuming the W79 JTA has approximately 2760 of these bonded wires the probabilities of failure are $0.0179 \%$ for virgin wedge bonds and $2.1 \%$ for post assembly tested wedge bonds. Therefore, further studies are recommended to identify the cause of wedge bond strength degradation during the post assembly environmental tests. 
CONTENTS

Introduction

Design L1mit Load Calculations "for Wedge and Ball Bonds

Conventional Loop-Hook Pull Test for Bond Joints

Normal Gaussian and Weibull Statistical: Analyse's for Bond

Strength Data

Weibul1 Analysis for Wedge Bond Strengths Obtained by Fixed Angle Pull Tests

Weibul1 Statistical Analyses for Virgin and Post-Assembly

Tested Wedge Bond Strength Dáta

Conclusions

REFERENCES 
ILLUSTRAT IONS

\section{Figure}

1 Finite-Element Model Mesh for Gold Wire Loop 12

2 Assumed Loop Geometry at Failure _ . . . 13

3 Deformed Finite-Element Mesh under Worst-Case Loading 14

4. Norma1 Cumulative Distribution Function (C.D.F.) of 21

$5 \quad$ Insert Portion of Normal C.D.F. 22

6 Normal Probability Density Function (P.D.F.) of Wedge 23 Bond Strength

7 Probability Density Function (P.D.F.) of Wedge Bond 25 Strength

8 Weibull Cumulative Distribution Function (C.D.F.) of Wedge Bond Strength

9 Enlargement of Portion of the C.D.F. (Weibull) for Wedge Bond Strength

10 Weibull Hazard Plot for Virgin Wedge Bond Strength ...

11 Weibull Cumulative Distribution Function for Virgin Wedge 35 Bond

12 Insert Portion on Weibull C.D.F. for Virgin Wedge Bond 36

13 Weibull Hazard Plot for Post Environmentally Tested . 38 Wedge Bond

14 Weibull C.D.F. for Post Environmentally Tested Wedge : 39 Bond

15 Insert Portion of Weibull C.D.F. for Post Environmentally 40 Tested Wedge Bond

16 Weibull Cumulative Distribution Functions (C.D.F.) of Wedge Bond Strength 


\section{ACKNOWLEDGMENTS}

The authors are grateful to R. J. Tockey and D. N. Bray for their encouragement and support for this study and to F. Uribe and G. A. Mayer for their assistance in testing. Appreciation is also due C. DeCarli and J. Cashen for their helpful comments and suggestions during the writing of this report. 
A request for detailed studies of the failure probability for gold wires bonded to multiplexer substrates under severe acceleration in the W79 artillery shell environments was made by R. J. Tockey (8461). The studies include (1) the calculated resultant pull forces exerted on the bond joints due to the W79 acceleration environments, (2) the suitability of the loop-hook pull tests and the use of the normal Gaussian distribution theory for statistical description of bond strengths, and (3) the probability of failure for gold wires bonded to multiplexer substrates under artillery shell accelerations using fixed angle pull tests and a Weibull distribution theory for the statistical description. 
The design limit loads for the wedge and ball bonds at the peak inertial loading of the wire are calculated by finite-element analysis. The inertial loadings of primary concern are the vector sums of peak setback axial acceleration loadings and centrifugal forces resulting from angular speed. For the W79 artillery shell the maximum setback axial acceleration (12000 $\mathrm{g}$ 's) and maximum angular velocity (1200 rad/sec) do not occur simultaneously. It has been determined that the worst case for wire loop loading occurs when the setback axial acceleration is a maximum, at which time the angular velocity has reached only $40 \%$ of its peak value. The resultant acceleration experienced by the wire for the W79 is $12,180 \mathrm{~g}$ 's.

A 1-mil diameter gold semi-conductor wire loop with 70-mil span was chosen for detailed finite-element analyses. Figure 1 shows the finite element model mesh for the wire. Only the net resultant forces and loading angles at the wedge bond and ball bond under maximum inertial loading are of interest and not bending moments or detailed stress distributions. From loop-hook pull tests it was observed that the wires are straightened to a triangular loop shape at failure (Figure 2). Large deflections tend to deform the gold wires which act as cables capable of carrying large tensile forces while carrying very little bending moment. Being concerned only with the in-plane net resultant forces at the bonds, the problem can be analyzed by a two-dimensional finite-element analysis. GNATS (General Non-linear Analysis of Two-dimensional Structures) is used for the analysis and the end forces for the wire are calculated assuming conditions of two-dimensional plane strain.

The mechanical properties for the gold wire material are:

$$
\begin{array}{ll}
\text { Young's Modulus, } & E=12 \times 10^{6} \mathrm{psi} \\
\text { Poisson's Ratio, } & v=0.3 \\
\text { Density, } & \rho=0.698 \mathrm{LB} / \mathrm{in}^{3}
\end{array}
$$

The deformed finite-element model for the wire is shown in Figure 3 for the W79 launch environment. The dotted line is the original shape and the solid line represents the true deformed shape under the worst case acceleration $\left(12,180 \mathrm{~g}^{\prime} \mathrm{s}\right)$ in the plane of the wire loop. The end force at the ball bond is $\left(F_{b}=0.17\right.$ gram and the angle $\left(\theta_{b}=45^{\circ}\right.$. The end force at the wedge bond is $\left(\mathrm{F}_{\mathrm{w}}=0.20\right.$ gram at an angle of $\left(\theta_{\mathrm{w}}=\right) 37.5^{\circ}$.

The natural frequencies of the same wire loop with 70-mil span were also calculated using the SAP4 finite-element code. Simple beam assumptions were used and out-of-plane motions were not constrained in the frequency analysis. 


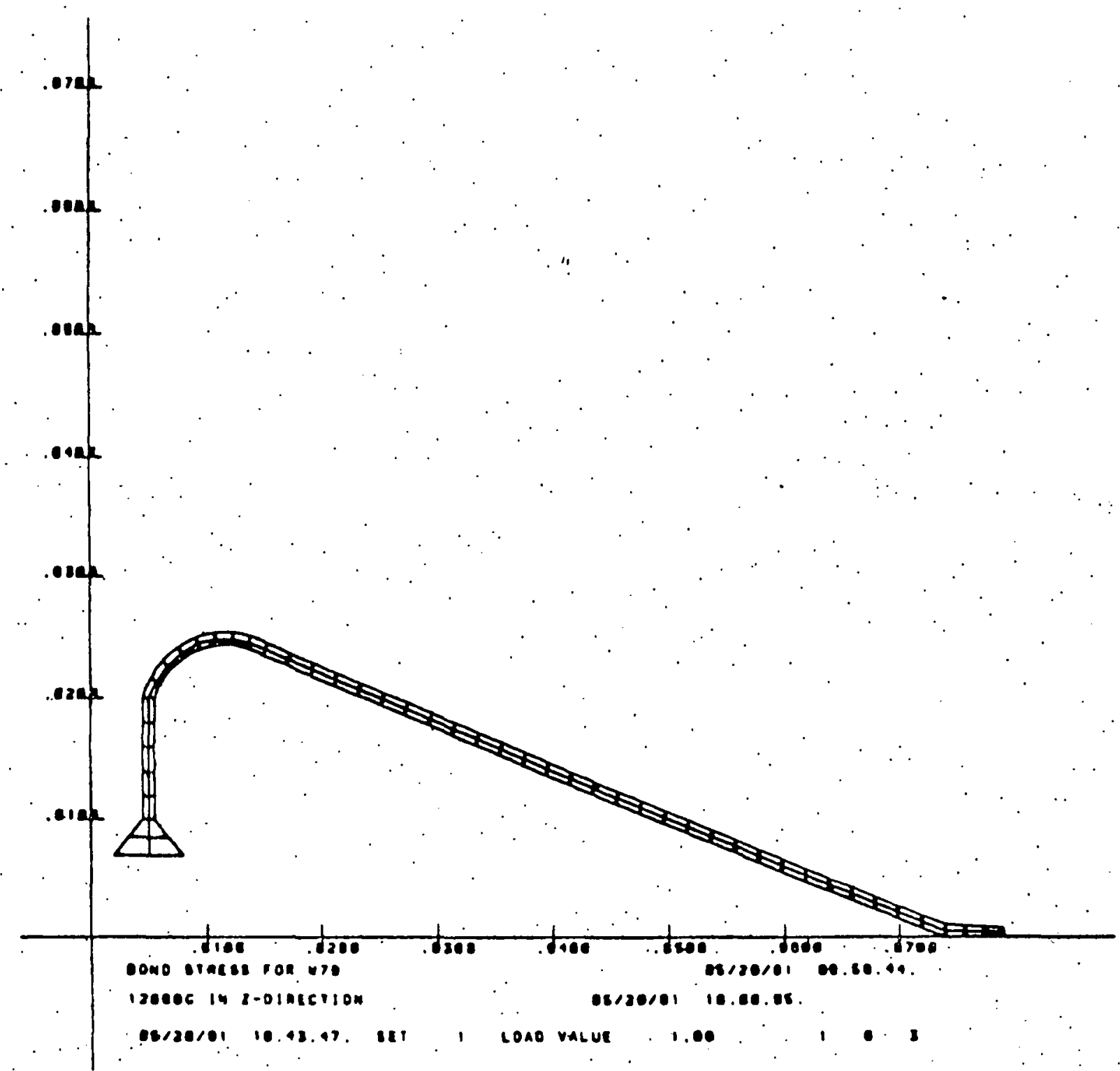

FIGURE 1. FINITE ELEMENT MODEL MESH FOR GOLD WIRE LOOP 


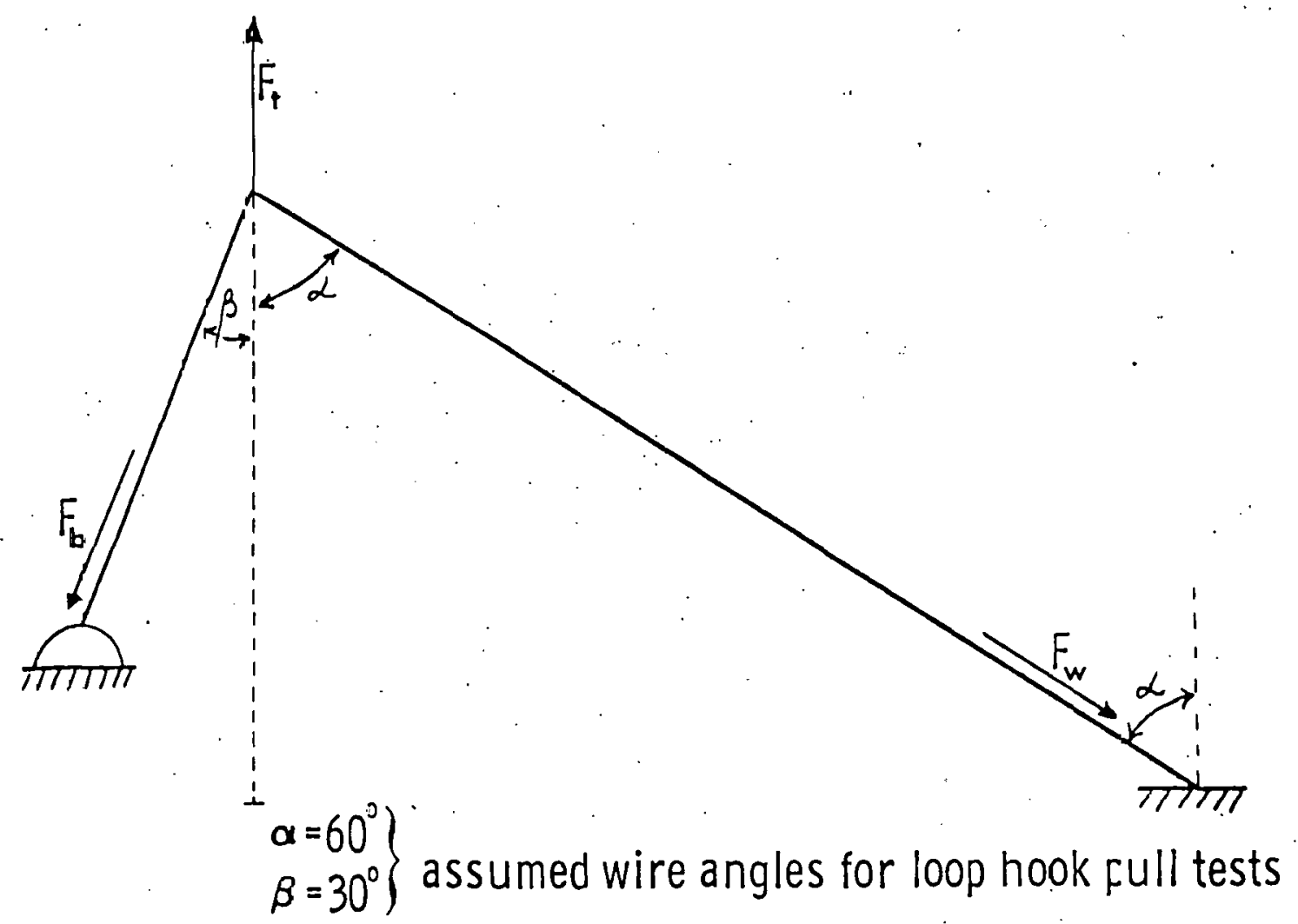




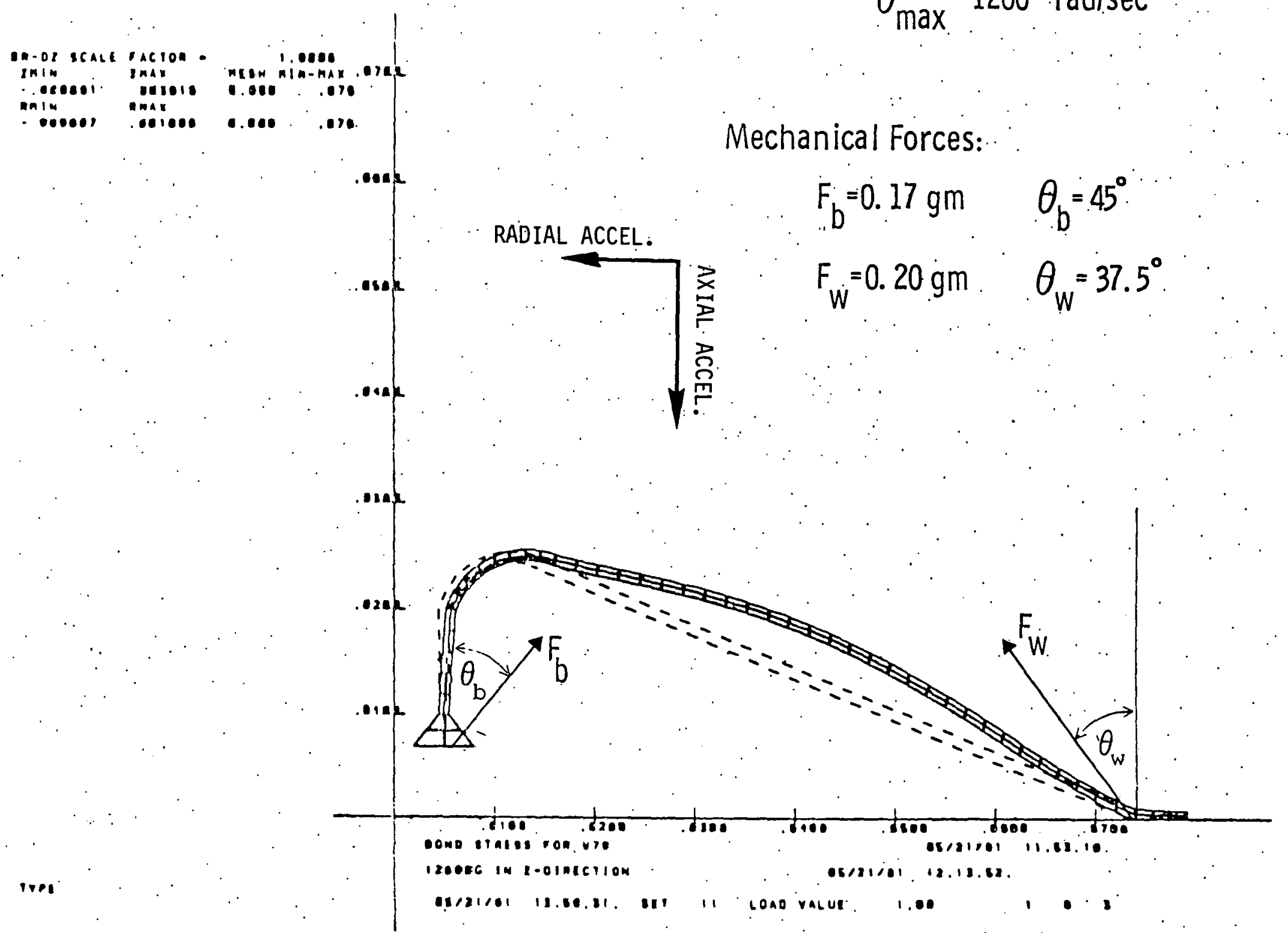

FIGURE 3. DEFORMED FINITE ELEMENT MESH UNDER WORST-CASE LOADING 
The first four lowest natural frequencies are listed in Table 1 .

TABLE 1. ANALYTICAL NATURAL FREQUENCIES (SAP4)

$$
\begin{array}{rlr}
\mathrm{f}_{1}=9,411 \mathrm{~Hz} & \text { (Out-Of-Plane) } \\
\mathrm{f}_{2}=12,940 \mathrm{~Hz} & \text { (In-Plane) } \\
\mathrm{f}_{3}=20,900 \mathrm{~Hz} & \text { (Out-Of-Plane) } \\
\mathrm{r}_{4}=40,390 \mathrm{~Hz} & \text { (Uut-Ut-Ylane) }
\end{array}
$$

The lowest frequency of the wire loop is more than one order of magnitude higher than the rotational frequency of the $679(\sim 195 \mathrm{~Hz}$.$) . Therefore,$ the gold wires are not expected to have resonant problems. The longest period, associated with the lowest natural frequency, is $\tau_{1}=1 / \mathrm{f}_{1} \simeq 0.1 \times 10^{-3}$ seconds. This justifies the use of a quasi-static analysis for the gold wires under setback axial acceleration and centrifugal acceleration since these have periods of $218 \times 10^{-3}$ seconds and rise times of about 5 to $6 \times 10^{-3}$ seconds so they will not excite any significant dynamic response. The only exception may occur on exiting the gun barrel where the axial acceleration drops to zero in the order $\sim 0.1 \times 10^{-3}$ seconds. At the end of the gun barrel, however, the axial acceleration is about one sixth (2000 $\left.\mathrm{g}^{\prime} \mathrm{s}\right)$ of its peak value and since the amplitude of this excitation is small the response is also expected to be very small. 
Using the bond loadings determined by the finite element analysis (Figure 3) as design limit loads along with experimentally measured bond strength data, we can predict the probability of failure at the design limit loads using a reasonable statistical model. The original data from Bendix Corp. [5] were the results of loop-hook pull tests on multiplexer substrates HMC ( $\mathrm{S} / \mathrm{N}$ 1022) with both ball and wedge bonds intact. In the wire loop-hook tests (Figure 2), the pull forces $\left(F_{t}\right)$ at failure were recorded but no measurements were taken for the loop geometry and wire angles ( $\alpha$ and $\beta$ ) relative to the vertical pull force. The wire angles are functions of wire length to span ratio and pull force location. The force components at the wedge bond $\left(F_{w}\right)$ and ball bond $\left(F_{b}\right)$ are highly dependent on these wire angles and are expressed by Equations ( $1 a$ ) and ( $1 b)$.

$$
\begin{aligned}
& \mathrm{F}_{\mathrm{w}}=\mathrm{F}_{\mathrm{t}} /\left[\cos (\alpha)+\frac{\sin (\alpha)}{\tan (\beta)}\right] \\
& \mathrm{F}_{\mathrm{b}}=\mathrm{F}_{\mathrm{t}} /\left[\cos (\beta)+\frac{\sin (\beta)}{\tan (\alpha)}\right]
\end{aligned}
$$

In this analysis, without measurements of pull angles at the bond sites, the geometry at failure was assumed to be as shown in Figure 2 with wire angles $(\alpha=) 30^{\circ}$ and $(\beta \Rightarrow) 60^{\circ}$. The bond strengths were calculated from the pull force $\left(F_{t}\right)$ to failure as:

$$
\begin{aligned}
& \mathrm{F}_{\mathrm{w}} \doteq 0.5 \mathrm{~F}_{\mathrm{t}} \\
& \mathrm{F}_{\mathrm{b}}=0.87 \mathrm{~F}_{\mathrm{t}}
\end{aligned}
$$


NORMAL GAUSSIAN AND WEIBULL STATISTICAL ANALYSES FOR BOND STRENGTH DATA

The common practice for analyzing the data on ball bond failure and data on wedge bond failure were assumed to follow a normal Gaussian distribution and the cumulative distribution function was fit to the discrete data in each case. The probability density function for the normal distribution is described by:

$$
\Phi(F)=\frac{1}{\sqrt{2} \pi S} \exp -\left(\frac{F-\bar{F}}{\sqrt{2} S}\right)^{2}
$$

and the cumulative distribution function is defined by:

$$
G(F)=\int_{-\infty}^{(F-\bar{F}) / S} \Phi(t) d t
$$

In general, the probability that the bond strength, $F_{w}$, lies between $F_{a}$ and $F_{b}$ is given by:

$$
P\left\{F_{a} \leq F_{w} \leq F_{b}\right\}=\int_{K_{a}}^{K_{b}} \Phi(t) d t=P\left(K_{a} \leq N \leq K_{b}\right) ; K_{i}=\left(F_{i}-\bar{F}\right) / S
$$

The bond strength data provided by Bendix consisted of 46 wedge bond failures, 98 ball bond failures for the multiplexer substrates summarized below:

$\mathrm{n}=$ number of bond failures

$\bar{F}=$ sample mean bond strength

$\mathrm{S}=$ sample standard deviation

$\mathrm{K}=$ percentage point of the normal distribution

N represents the normal probability density function

WEDGE BOND

$\mathbf{n}=46$

$\bar{F}_{\mathrm{w}}=2.54 \mathrm{gm}$.

$\mathrm{s}_{\mathrm{w}}=0.968 \mathrm{gm}$.

$\mathrm{F}_{\mathrm{w}_{\text {design }}}=0.2 \mathrm{gm}$

$\mathrm{K}_{\mathrm{w}}=\left(\overline{\mathrm{F}}_{\mathrm{w}}-\mathrm{F}_{\mathrm{w}_{\text {des }}}\right) / \mathrm{S}_{\mathrm{w}}=2.417$

$P\left(F_{W} \leq 0.2\right)=P(N \geq 2.417)=0.0078$
$\underline{B A L L} \underline{B O N D}$

$$
\mathrm{n}=98
$$

$\overline{\mathrm{F}}_{\mathrm{b}}=4.36 \mathrm{gm}$.

$\mathrm{s}_{\mathrm{b}}=0.78 \mathrm{gm}$.

$\mathrm{F}_{\mathrm{b}_{\text {design }}}=0.17 \mathrm{gm}$.

$\mathrm{K}_{\mathrm{b}}=\left(\overline{\mathrm{F}}_{\mathrm{b}}-\mathrm{F}_{\mathrm{b}_{\text {des }} .}\right) / \mathrm{S}_{\mathrm{b}}=5.37$

$P\left(F_{b} \leq 0.17\right)=P(N \geq 5.37)<.0001$ 
The probability of failure of the ball bond for forces at or below the $0.17 \mathrm{gm}$. design limit load was negligible. The probability of failure for the wedge bond, however, at loadings less than or equal to its design limit load of $0.2 \mathrm{gram}$ is .0078 and considered too high. The normal cumulative distribution function (c.d.f.) of wedge bond strength is shown in Figure 4 over the discrete values and an inset portion for small $\mathrm{F}_{\mathrm{w}}$ is shown in Figure 5 . A disadvantage in using the normal distribution to represent the data is seen here for there is a small finite probability of fallure for the wedge bond at negative strengths (.0044). This feature makes no physical sense, and a probability as high as nearly .0044 for bonds with strength less than zero was unrealistic. The general shape and characteristic of the density function extending beyond the zero bond strength are further illustrated in Figure 6.

Due to this major drawback of predicting a significant amount of negative bond strength by normal Gaussian distribution, a Weibull distribution was fit to the data for wedge bonds. Initial results for ball bonds were convincing enough to consider these satisfactory; but the failure probability for the wedge bond was not acceptable. Recently the Weibull distribution has become more popular for representing strengths of various brittle solids, it has been satisfactory for time-to-failure models on empirical grounds, and for representing distributions for life test data on electron tubes, ball bearings, relays, and capacitors. In other instances, the use of the Weibull distribution to represent the distribution of breaking strength of materials has been justified [2].

The Weibull probability density function (p.d.f.) is of the form:

$$
\Phi(F)=\left\{\begin{array}{lc}
\frac{M}{S^{\top}}\left(\frac{F-\bar{F}}{S^{\prime}}\right)^{M-1} \exp -\left(\frac{F-\bar{F}}{S^{\prime}}\right)^{M} ; & M>0, S^{\prime}>0, \bar{F}>0, F \geq \bar{F} \\
0 \quad & ; F<\bar{F}
\end{array}\right.
$$

and the c.d.f. is of the form:

$$
G(F)=\int_{-\infty}^{F} \Phi(F) d F= \begin{cases}1-\exp -\left(\frac{F-\bar{F}}{S^{\prime}}\right)^{M} & ; M>0, S^{\prime}>0, \bar{F}>0, F \geq \bar{F} \\ 0 & ; F<\bar{F}\end{cases}
$$

where $M$ is known as the Weibull slope or shape parameter, $S^{\prime}$ is the characteristic strength or scale parameter, and $F$ is the lower bound of strength or the location parameter. Normally, the Weibull distribution is a three parameter distribution as shown above, but one parameter has been defined by the reasons for the choice of the Weibull. Namely, the lower bound of strength is assumed, for physical reasons, to be zero. It has been found in previous cases dealing with material strengths and fatigue life data concerning mechanical components that this is a good assumption (1). The remaining parameters are to be determined from experimental bond strength test data. 


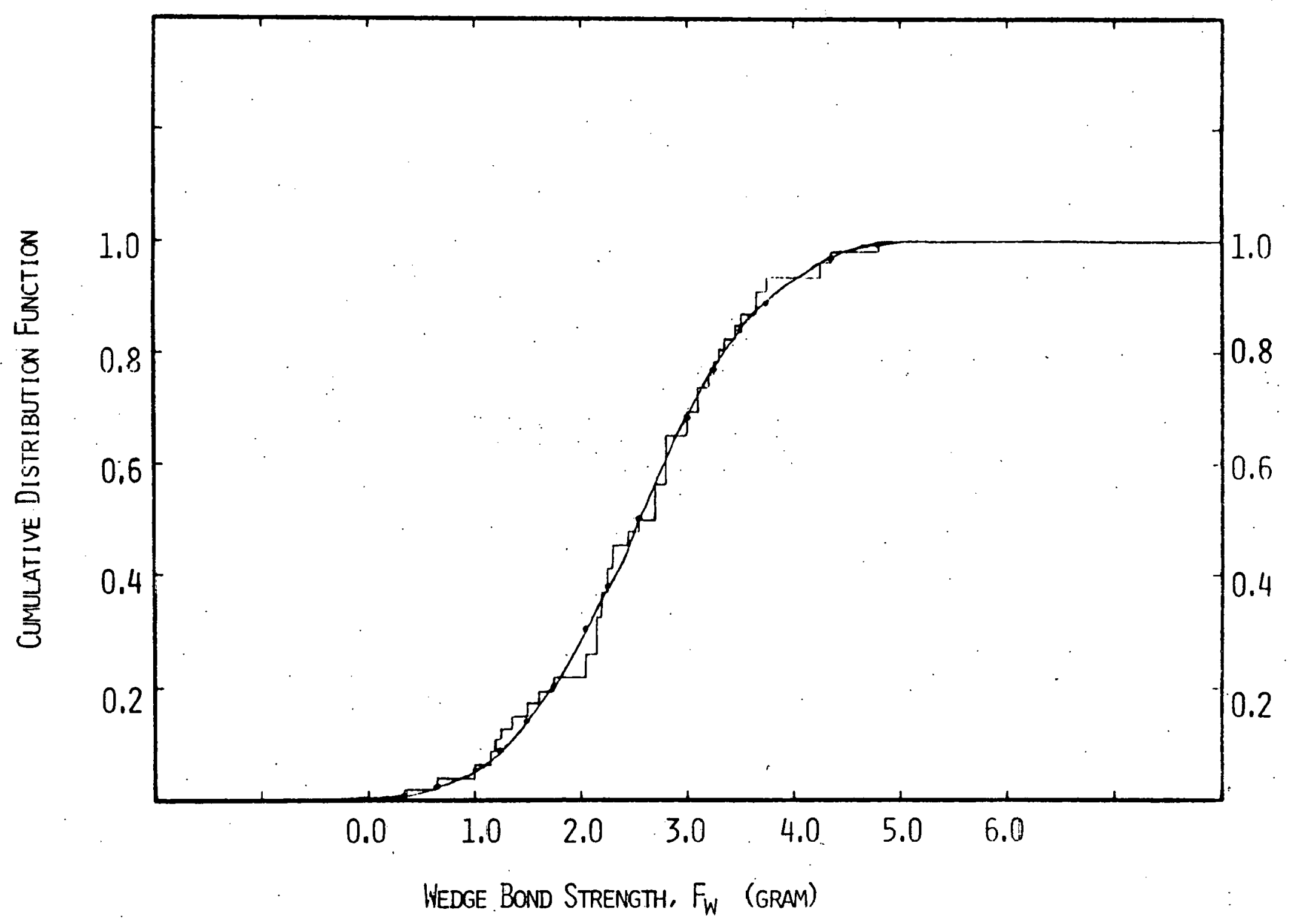




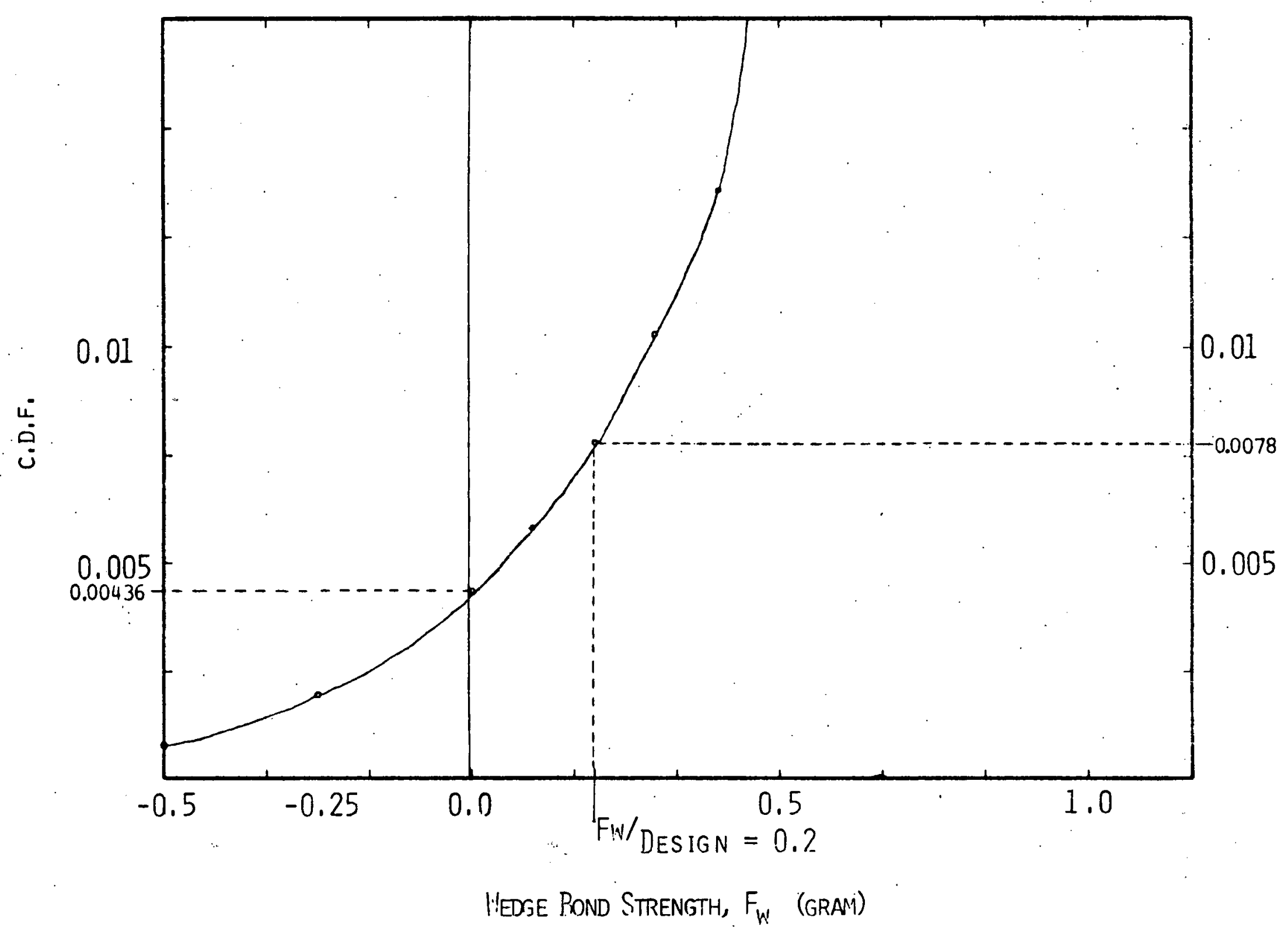

FIGURE 5. INSERT PORTION OF NORMAL C.D.F. 


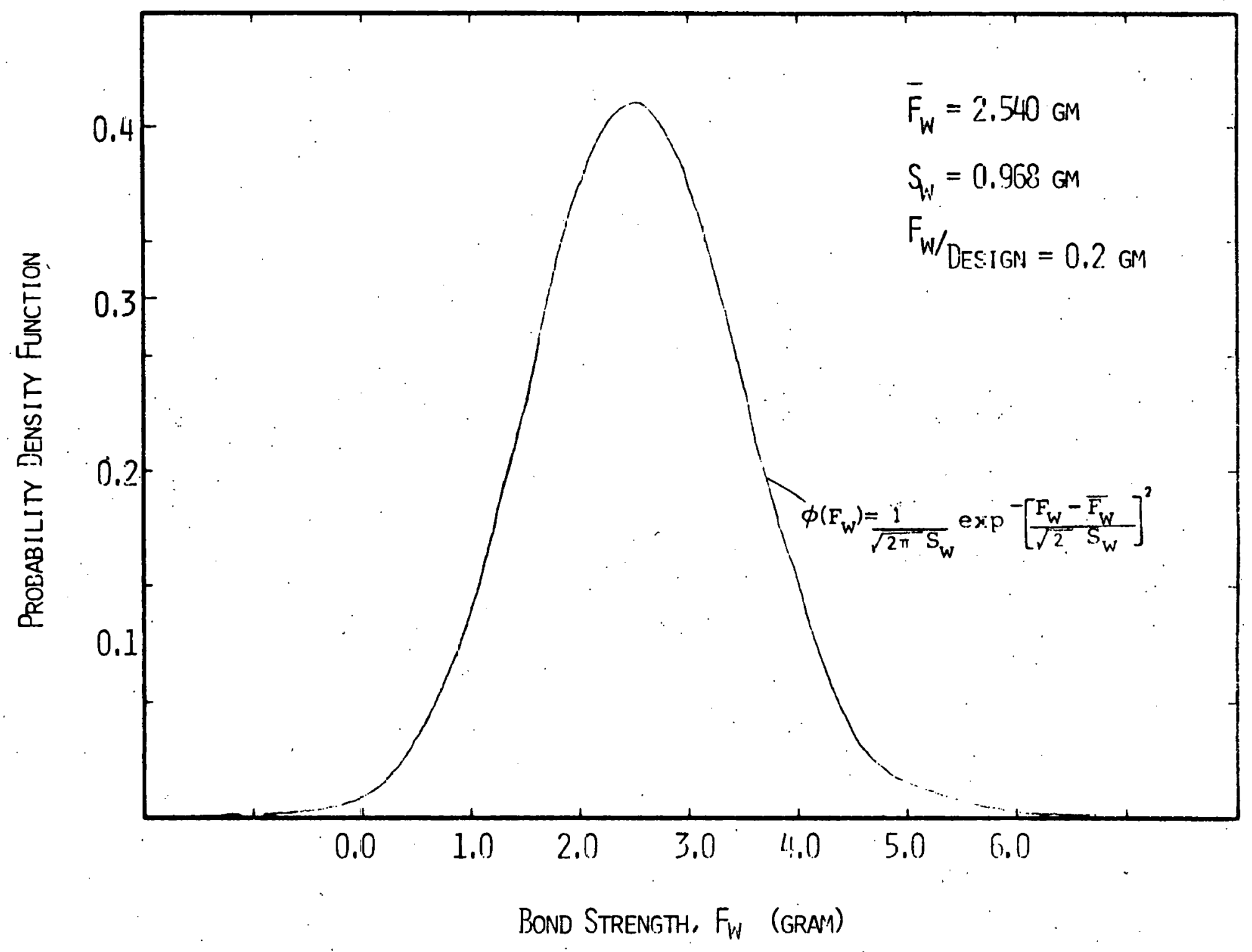

FIGURE 6. NORMAL PROBABILITY DENSITY FUNCTION (P.D.F.) OF WEDGE BOND STRENGTH 
A major advantage in working with the Weibull distribution is that a location parameter of zero eliminates any probably negative bond strengths, unlike the case with the normal Gaussian distribution. A final argument for using the Weibull distribution is based on a key assumption of the "weakest link hypothesis" [1]. The bond may be modelled as not being of uniform strength due to inherent flaws in the bond material and in application of the wires. The distribution of the flaw strengths in any bond is unknown mainly due to the fact that the flaws are often too small to detect. The assumption is made that the bond fails when the strength of the weakest portion has been exceeded [3]. In this manner a distribution of the strengths of the most severe flaws (among the many in each bond) can be obtained. The breaking strength of a bond, then, is assumed to be the strength of its greatest flaw, the smallest local strength of the bond.

The distribution of the smallest (extreme) values in a sample size of $n$ has been analyzed by Gumbel and others in detail and as the sample size $n \rightarrow \infty$, three forms of distribution are possible of which only one is bounded to the 1eft. This is known as a Type III asymptotic distribution (Weibull)[3]. Furthermore, if the distribution of flaw strengths within a single bond is such that it can be assumed no flaw has negative strength it will be bounded from the left. Then the distribution of the smallest values for flaw strength will follow a similar distribution, that is a Type III distribution such as the Weibull as opposed to a Type I distribution such as the normal (unbounded to the left). With such reasoning, one can be more confident in attempting a Weibull fit.

Taking the Weibull cumulative distribution function (c.d.f.) of two unknown parameters and equating this with a generally accepted expression for the expected value of ordered observations given by

$$
\frac{(i-c) 100}{n-2 c+1}=G(x) ; c \text { depends on } n \text { and } \Phi\left(F_{w}\right)
$$

one may solve for the Weibull parameters where the data are ranked $i=1$ to $n$ in increasing order of bond strengths. Normally a value of one-half $(1 / 2)$ or zero is chosen for $c$ depending on the author. Here Gumbul's approach $(c=0)$ is taken and the parameters are calculated. The Weibull p.d.f. is illustrated in Figure 7 with zero probability for negative wedge bond strength. The c.d.f. for the 46 data points and an enlarged portion in the region about the design limit load are shown in Figures 8 and 9 respectively. The probability of wedge bond strengths less than or equal to the design limit load of $0.2 \mathrm{gm}$. is $0.21 \%$. This value was not satisfactory and so it was decided to perform a series of more carefully run experiments on the wedge bond at a fixed pull angle and fit the data to a Weibull distribution. It should be noted that the characteristics of the bond strength data obtained from the loop-hook pull tests and calculated using equation (2) will be different from the characteristics of bond strengths obtained from fixed-angle pull tests since the angles in the loop-hook pull tests are varying from wire to wire and have their own statistical characteristics which are ignored when assuming the geometry at failure. The variation in loop-pull angles may 


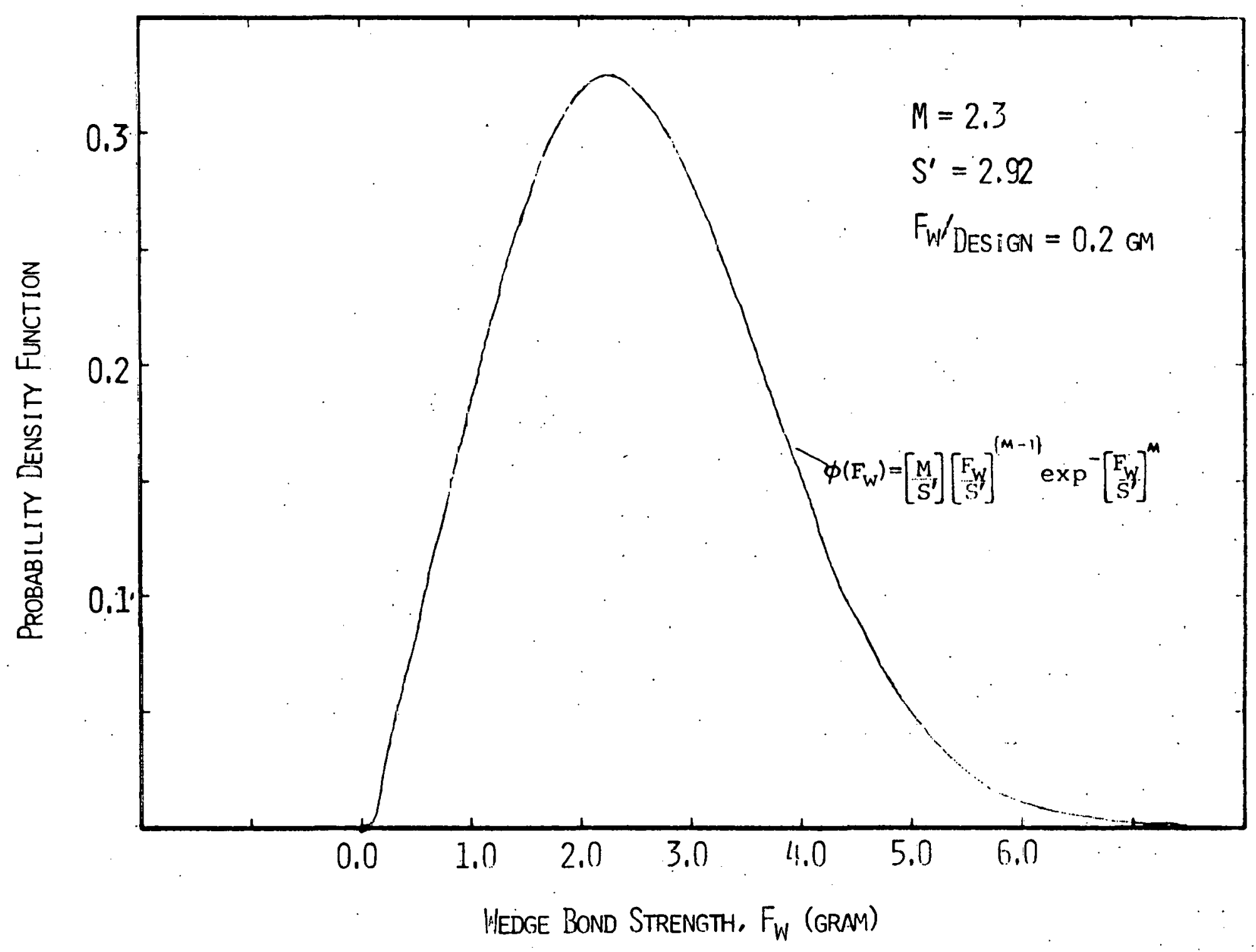

N

FIGURE 7. PROEABILITY DENSITY FUNCTION (P.D.F.) OF WEDGE BOND STRENGTH 


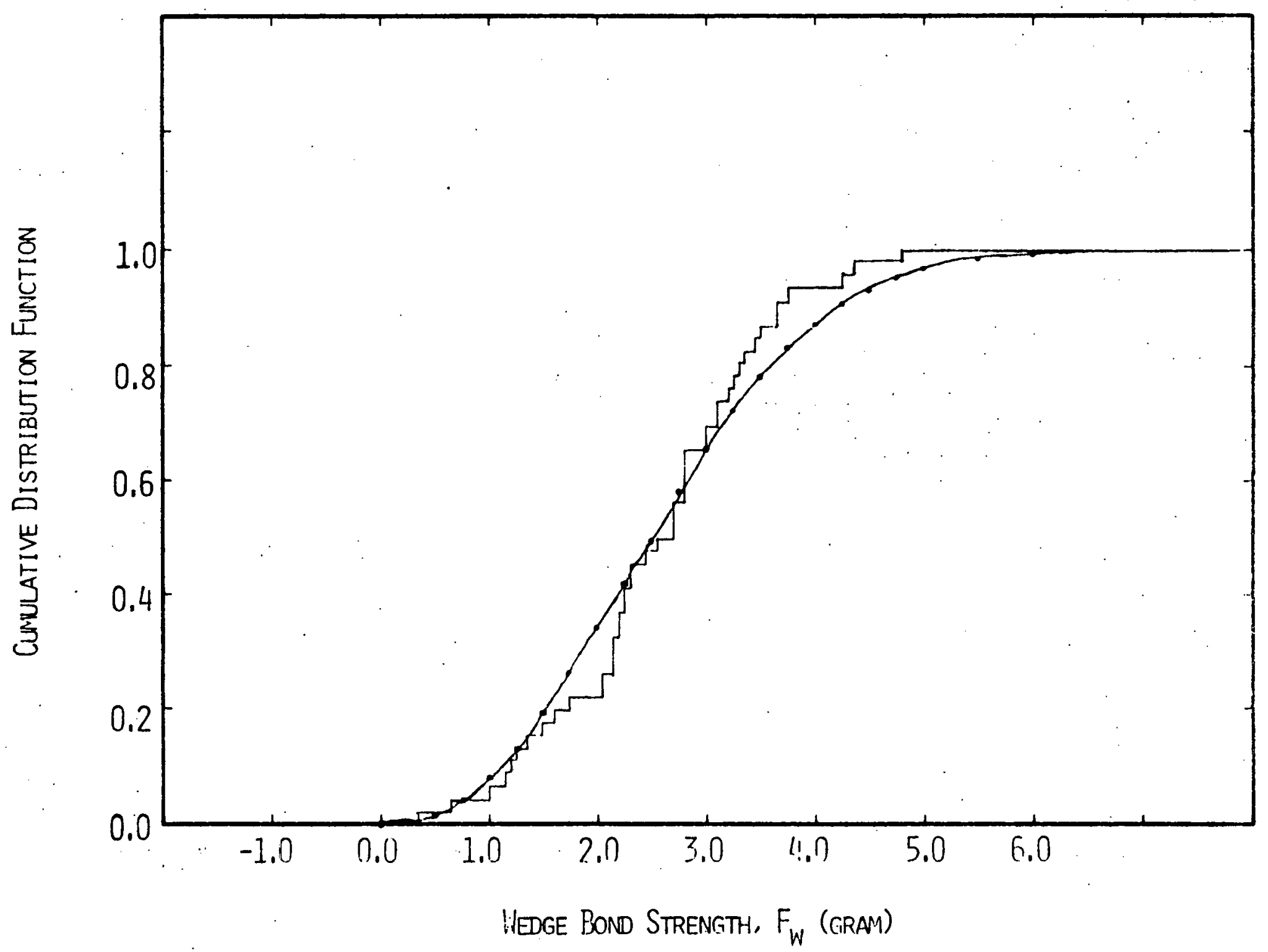

FIGURE 8. WEIBULL CUMULATIVE DISTRIBUTION FUNCTION (C.D.F.) OF WEDGE BOND STRENGTH 


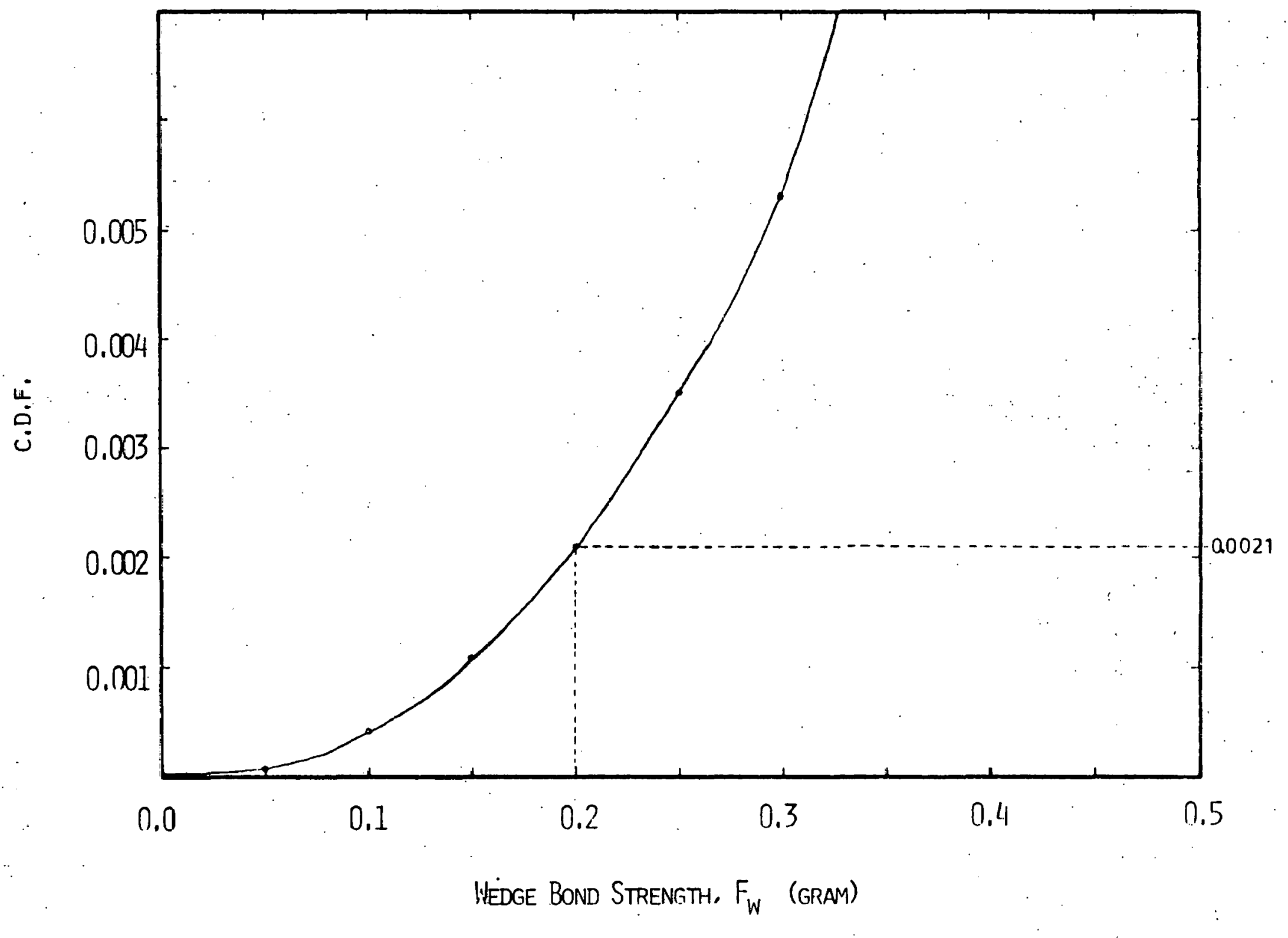

FIGURE 9. ENLARGEMENT OF PORTION OF THE C.D.F. (WEIBULL) FOR WEDGE BOND STRENGTH 
cause mean values for bond strength to be either higher or lower than the true mean bond strength but their varlances.will always be greater than the true variance. This uncertainty for the wire angles in the wire loop pull tests increases the spread of the data and this spread results in inaccurately high predicted probabilities for failure in the low load range. 
The tests consisted of cutting the wire loop near the ball bond and pulling the right hand downward sloping portion of the wire in Figure 2 at an angle $\alpha=30^{\circ}$. These tests were completed with larger sample sizes $(n=112,133)$. There are only two failure modes, wedge bond and wire failures (ball bond is no longer part of the test). The measured strength was analyzed by a hazard statistical analysis. The method of hazard plotting was introduced to enable one to make use of the data on all modes of failure in the statistical analysis. The method is described by Nelson [4] as a graphical technique available for analyzing censored (incomplete) failure data via a hazard function.

The hazard function is a conditional probability function or conditional failure function which expresses the proportion of the unfailed wedge bonds at $F_{w}$ that will fail in the interval $\left(F_{w}, F_{w}+d F_{w}\right)$. Hazard functions correspond to specified distributions and for the Weibull it can be represented

$$
h\left(F_{w}\right)=\frac{\Phi\left(F_{w}\right)}{1-G\left(F_{w}\right)}=\frac{M}{S^{\prime}}\left(\frac{F}{S^{\prime}}\right)^{M-1}
$$

and the cumulative hazard function by:

$$
H\left(F_{w}\right)=\int_{-\infty}^{F_{w}} h\left(F_{w}\right) d F_{w}=\left(\frac{F_{w}}{S^{\top}}\right)^{M}
$$

Sample cumulative hazard values at specific bond strengths can be calculated by the methods presented by Nelson [4], and a straight line plot of cumulative hazard vs. bond strength on log-log paper is characteristic of the Weibull distribution. Such a plot can be used to determine the Weibull parameters.

The chief advantage in utilizing hazard plotting is that it uses all strength data in both fallure modes for evaluating the wedge bond strength characteristics. While it assumes the failure modes to be statistically independent, the analysis is based on the reasoning that each semi-conductor wire loop has a wire strength and a wedge bond strength, and that only the smaller of the two can be observed for each loop tested. For purposes of the analysis, all the data points may be used when a wire failure is viewed as a result of a test which did not reach the actual wedge bond strength before failure. Namely, the wedge bond strength is higher than the pull force at which the wire failed. These reported failure strengths are called censoring values for the wedge bond strength [4], and are used in determining hazard values. 
WEIBULL STATISTICAL ANALYSES FOR VIRGIN AND POST-ASSEMBLY TESTED WEDGE BOND

STRENGTH DATA

The virgin wedge bond strength data, botained by fixed-angle pull test, are listed in Table 2. The total number of data points is 133 and the measured strengths range from 2.0 grams to 8.5 grams. Twelve out of 133 points are wire failure and lowest strength in wire failure is 7.25 grams; the highest is 8.5 grams. The mode of fallure is indicated by descriptors ( 1 for wire failure, 0 for bond failure). . This relatively narrow range in wire strength reflects that gold wire is relatively undamaged during the bonding, laser cutting at the ball bond prior to the fixed-angle pull testing. The 12 wire failure data points, ranging from 7.25 to 8.5 grams, do not give the exact strengths of the wedge bonds, however, they have shown that their wedge bonds are either equal or stronger than their measured wire strengths. This fact is appropriately taken into account by the use of hazard function, which is a conditional probability function. The relationships between the accumulated hazard function and accumulated distribution function is

$$
H\left(F_{w}\right)=-\ln \left(1-G\left(F_{w}\right)\right)
$$

Using the complete data (both wire and bond failures) for the virgin wedge bond, a least-square $f$ it is used to calculate the Weibull characteristic strength $\left(S^{\prime}=6.55 \mathrm{gm}.\right)$ and shape $(M=4.742)$. The predicted cumulative distribution for the virgin wedge bond is

$$
G\left(F_{w}\right)=1-\exp -\left(\frac{F_{w}}{6: 55}\right)^{4.742}
$$

The Weibull cumulative hazard plot for the virgin wedge bond data points are shown in Figure 10. It is very close to a straight line in $10 \mathrm{~g}$ versus $10 \mathrm{~g}$ plot, as expected for a good Weibull distribution. The predicted cumulative distribution function versus wedge bond strength data are plotted in Figure 11, again the fit. between the measured bond strengths and Weibull distribution is very good. The extrapolation for the cumulative distribution to very low bond strengths is shown in Figure 12 and it predicted that failure probability for the virgin wedge bond at or below 0.2 gram design limit load for W79 system is about $6.53 \times 10^{-6 \%}$.

The strength data for the wedge bonds which have undergone the post assembly environmental tests are listed in Table 3. The total number of data points is 112. The mode of failure is indicated by descriptors ( 1 denotes wire failure, 0 denotes bond failure). The bond strength ranges from 1.6 grams to 8.0 gram. There is a total of ten wire failures and the wire strength. ranges from 6.8 grams to 8.0 grams. Using a least-square fit for the tabulated wedge bond strength data to the Welbull cumulative hazard function, we can obtain the Weibull strength $S^{\prime}(=6.337 \mathrm{gm}$.$) and shape M(=3.410)$. The 
predicted Weibull cumulative distribution function for the post assembly environmental tested wedge bond is

$$
G\left(F_{W}\right)=1-\exp \left(\frac{F_{w}}{6.337}\right) 3.410
$$

The Weibull cumulative hazard plot for the.wedge bond strength data are plotted in Figure 13. It is very close to a straight line in log versus $\log$ plot; this is an indication of good Weibull distribution. The cumulative distribution functions for the predicted Weibull distribution and the discrete sample are plotted in Figure 14 and the fit is very good. The extrapolation of the cumulative distribution function to very low. bond strength is shown in Figure 15 and it predicts that the post assembly environmentally tested wedge bond has a probability of failure at or below 0.2 gram (design limit load for the W79) of $7.6 \times 10-4 \%$. The degradation in probabilities of fallure at 0.2 gram limit load, from $6.3 \mathrm{x} \cdot 10^{-6 \%}$ for a virgin wedge bond to $7.6 \times 10-4 \%$ for the post assembly environmentally tested wedge bond, is very significant even though they are obtained by. extrapolations of predicted Welbull distributions. Figure 16 plots the discrete bond strength data and Weibull distributions for virgin (preenvironment) and post assembly tested (post-environment) wedge bonds. It is very clear that the difference in bond strength at low load range is very significant. Similar experiences of wire bond degradation was recently reported for the B61 JTA HMC (P/N 239376, S/N 1009) substrates wire bonds [6] [7]. Further experimental and analytical studies are recommended to identify the cause of bond strength degradation. 
TABLE 2. VIRGIN WEDGE BOND STRENGTH DATA

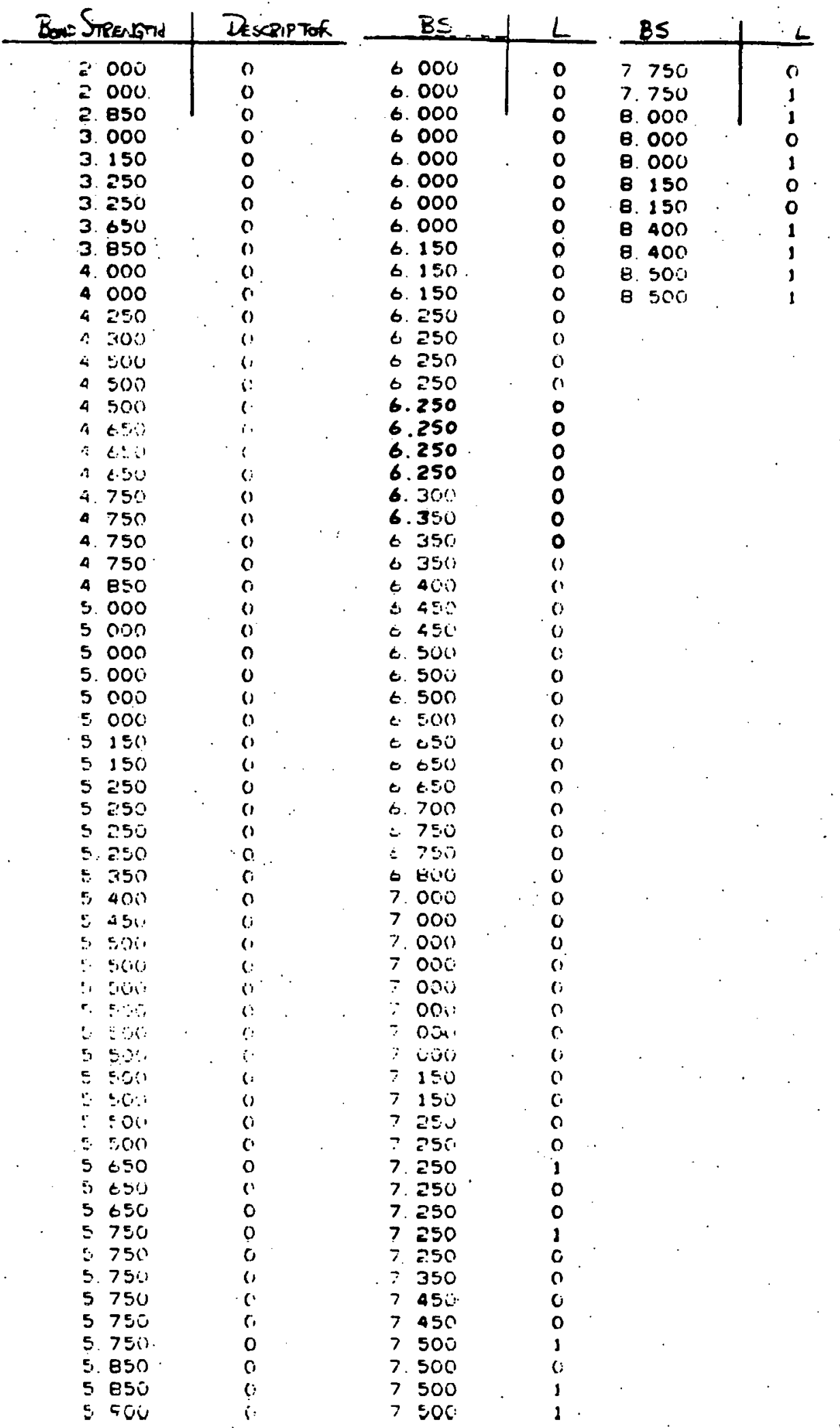




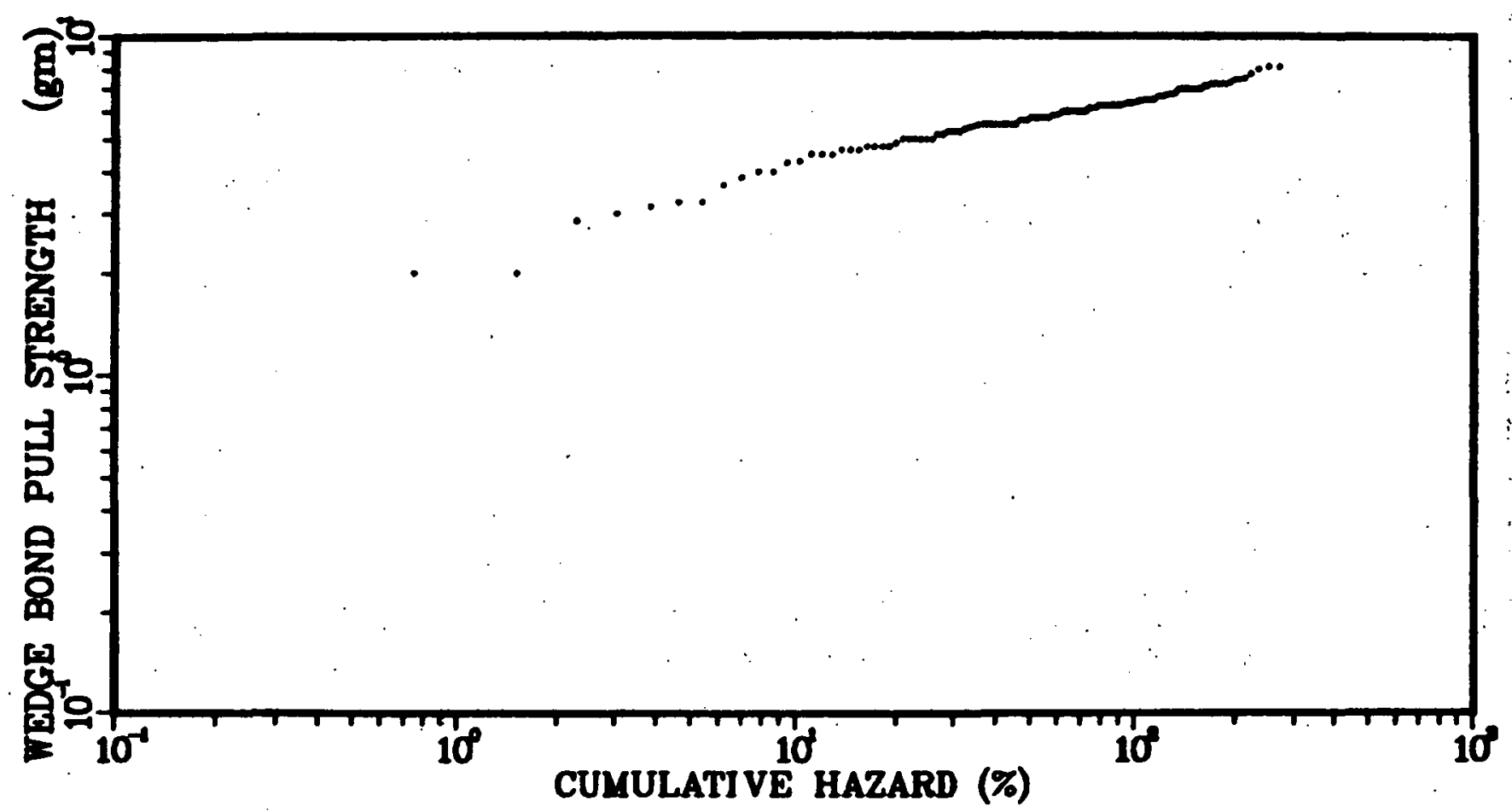

FIGURE 10. WEIBULL HAZARD PLOT FOR VIRGIN WEDGE BOND STRENGTH 


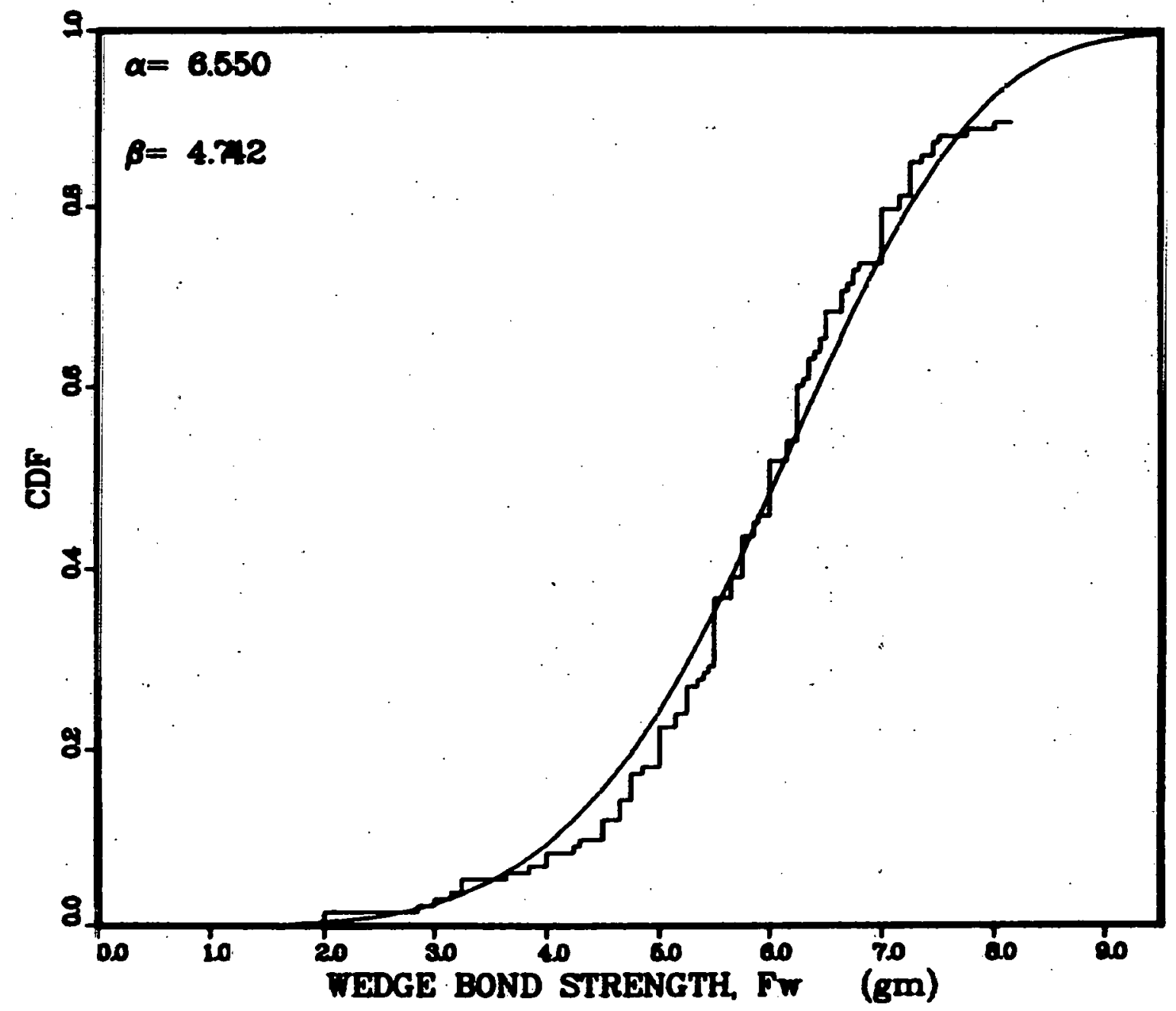




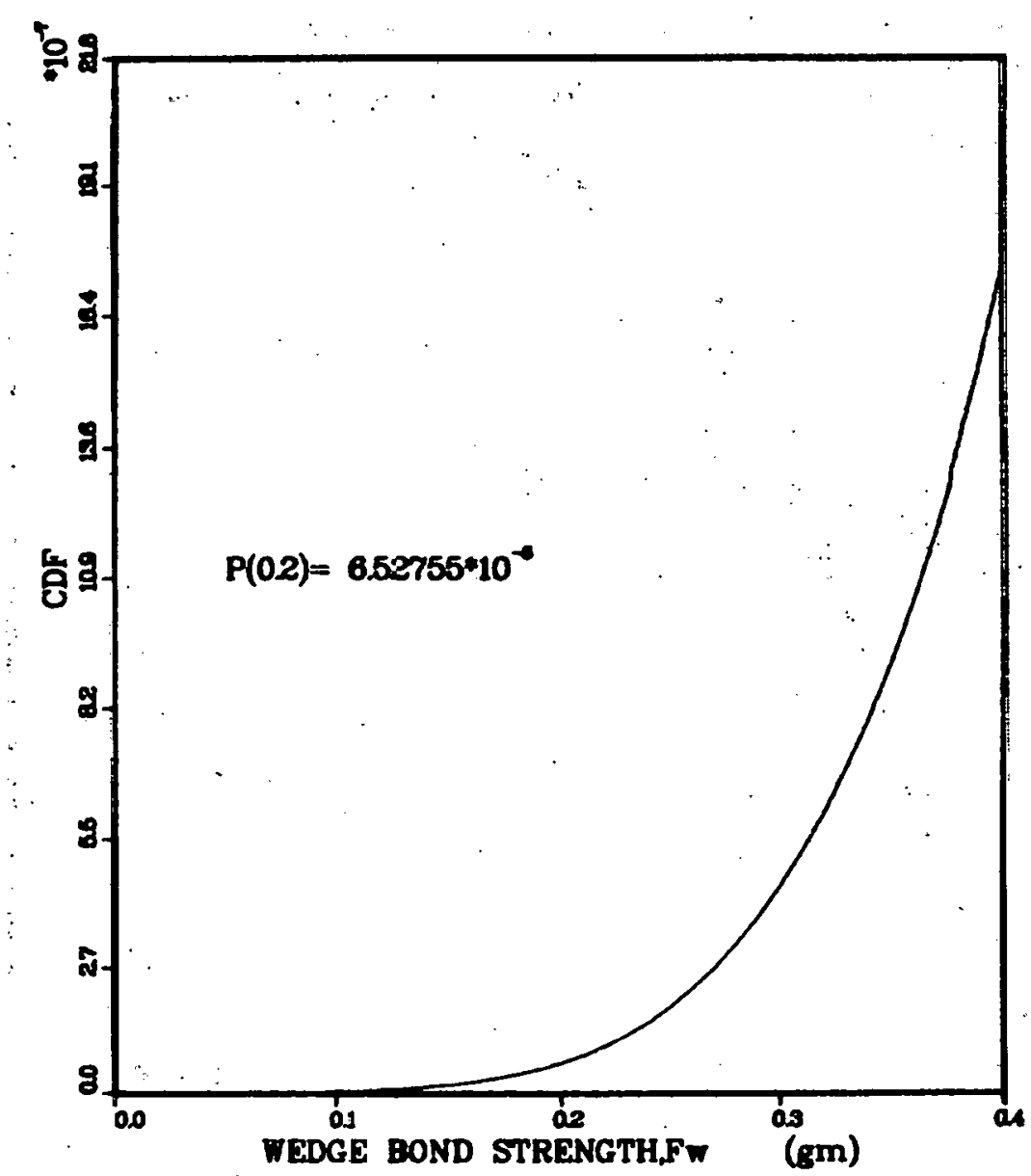

FIGURE 12. INSET PORTION OF WEIBULL CDF FOR VIRGIN WEIGE BOND 
TABLE 3. POST ASSEMBLY ENVIRONMENT TEST WEDGE BOND STRENGTH DATA

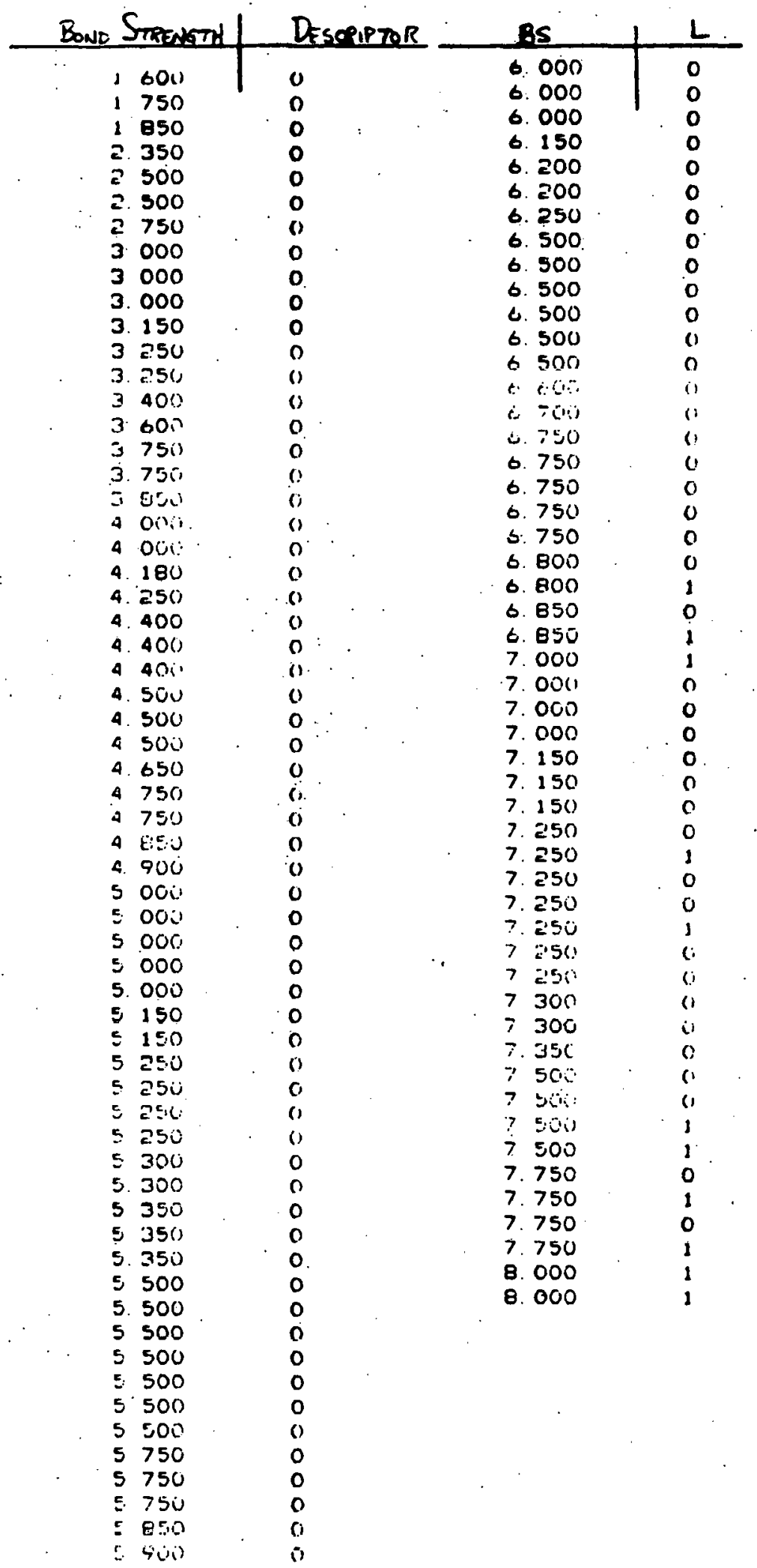




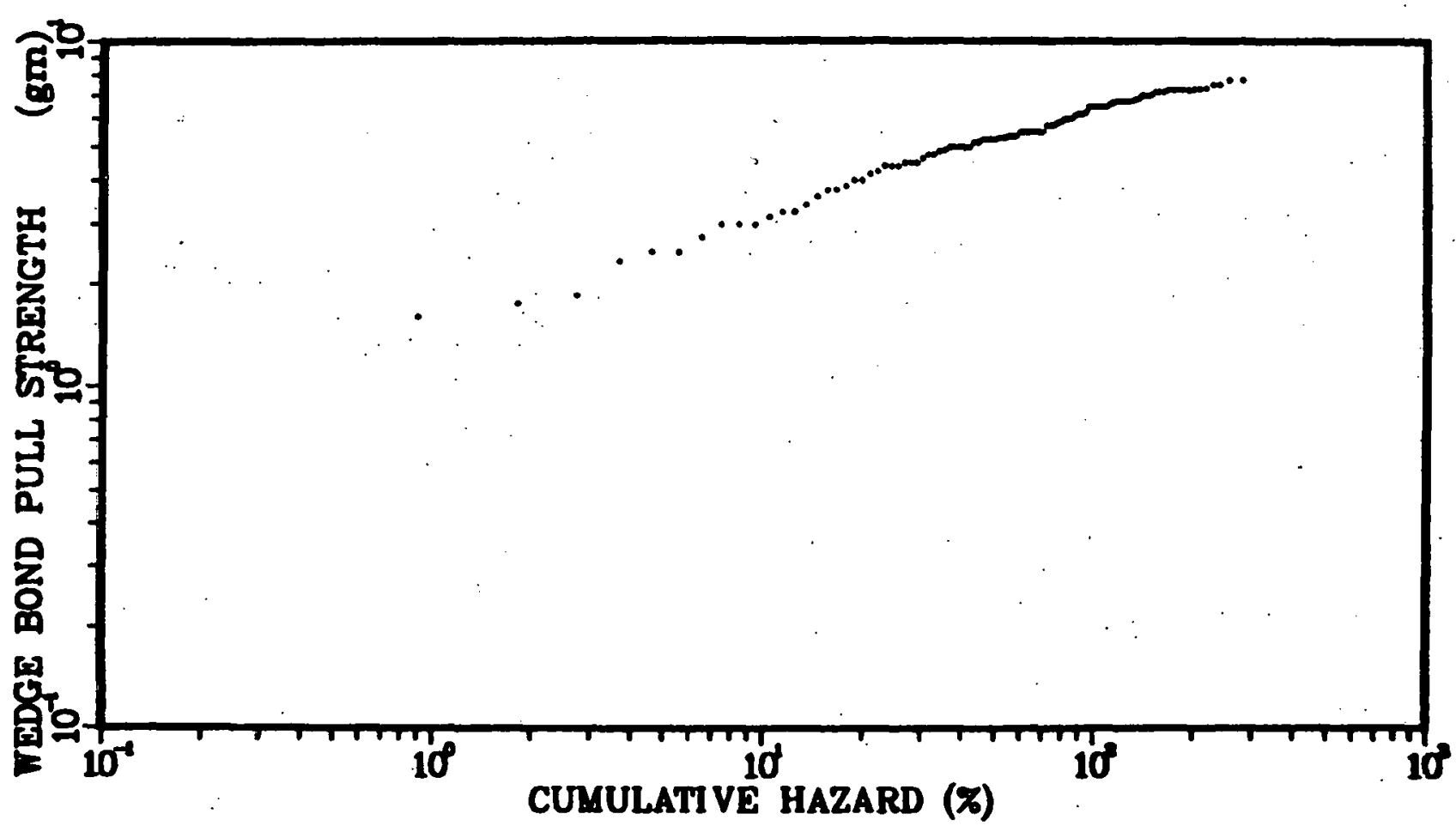




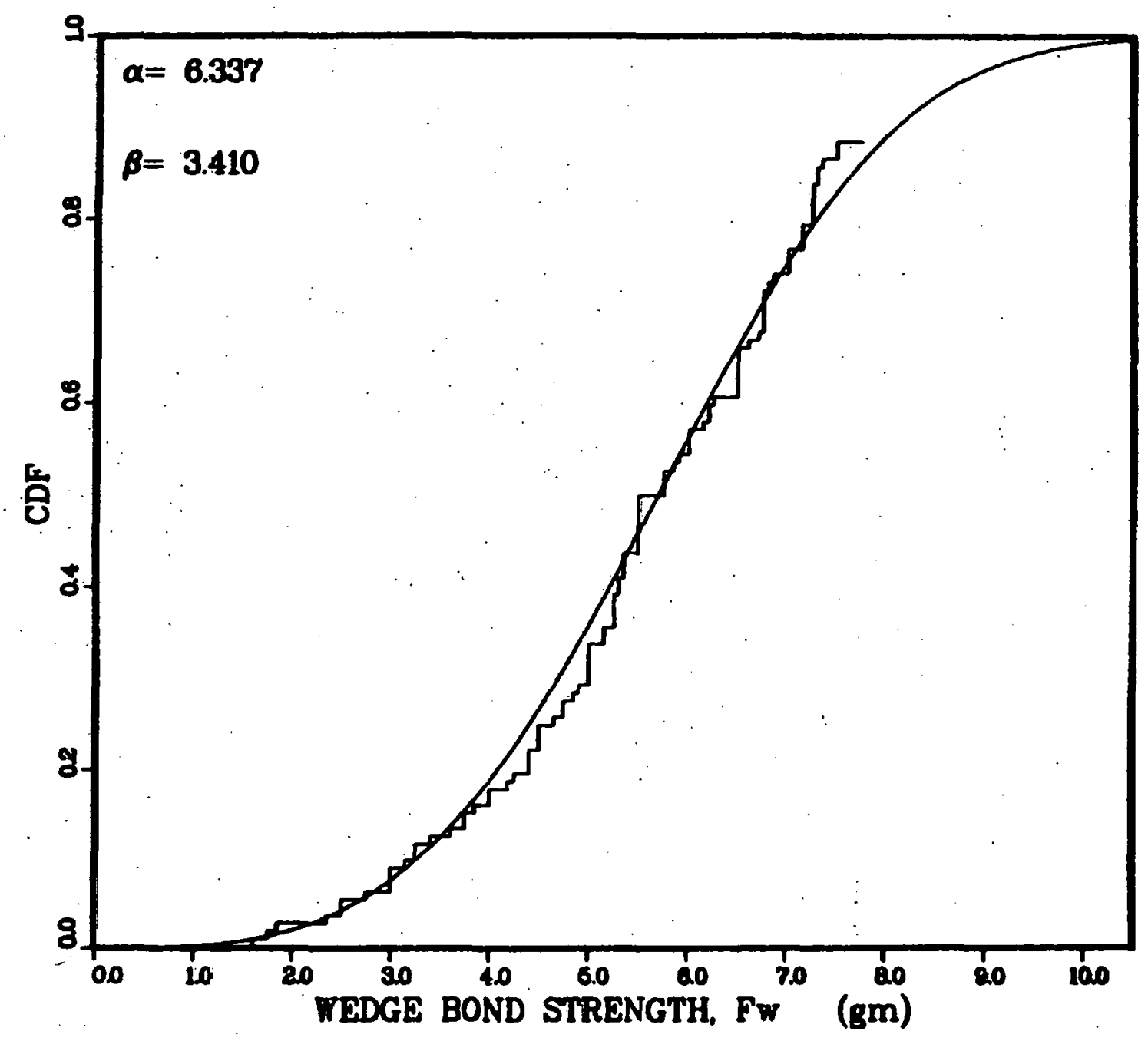
TESTED WEDGE BOND 
t

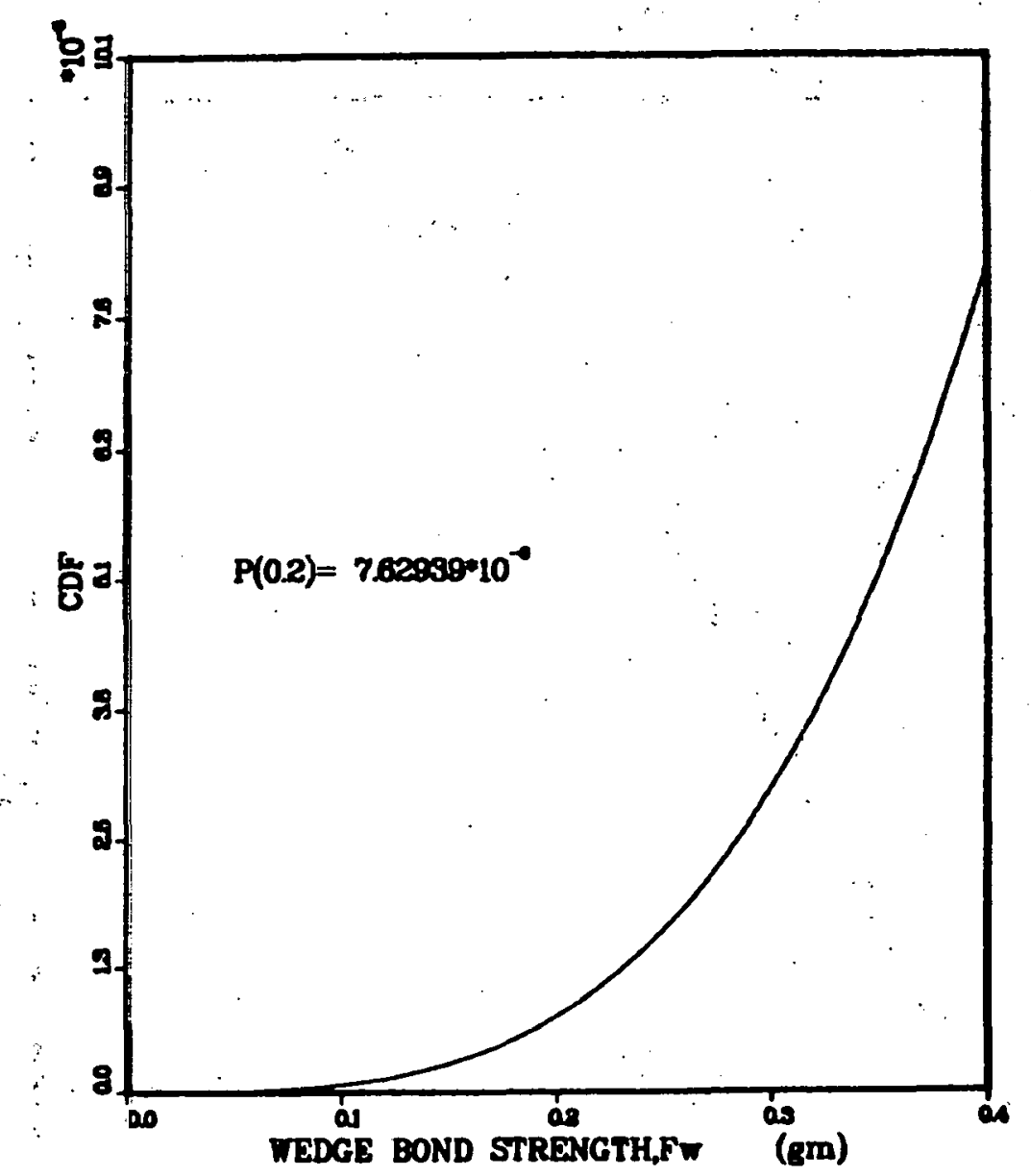

FIGURE 15. INSERT PORTION OF WEIBULL C.D.F. FOR POST ENVIRONMENTALLY TESTED WEDGE BOND 


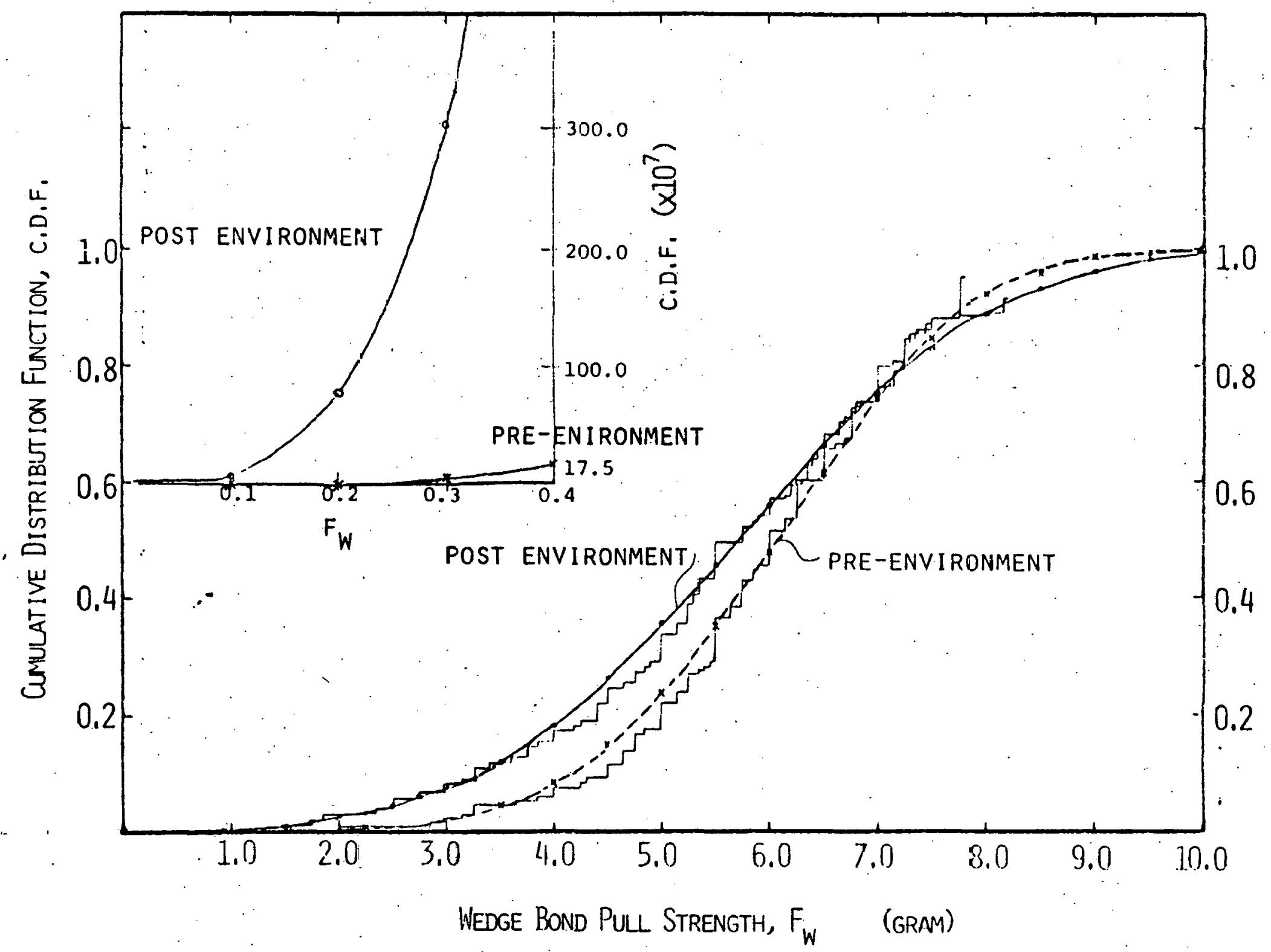

FIGURE 16. WEIBULL CUMULATIVE DISTRIBUTION FUNCTIONS (C.D.F.) OF WEDGE BCIND STRENGTH 


\section{CONCLUSION}

Under the W79 acceleration environment of $12,000 \mathrm{~g}^{\prime} \mathrm{s}$, the pulling forces on the ball and wedge bonds for a 1-mil dlameter gold wire with a span of 70-mil are calculated by finite element analyses and are found to be $0.17 \mathrm{gm}$. and $0.20 \mathrm{gm}$., respectively. The bond strength data for multiplexer substrates acquired by Bendix using a conventional loop-hook test method and analyzed using standard normal and Weibull statistical distributions have shown that the wedge bond has an unacceptably high probability of failure at $0.2 \mathrm{gm}$., the calculated W79 design limit load for the wedge bond. Further studies using Welbull statistical theory to analyze wedge bond strength data obtained from fixed-angle pull test revealed that the wedge bond strength is much less scattered than that obtained by loop-hook pull tests. The probability of wedge bond fallure for a required pull force of $0.2 \mathrm{gm}$. or less is $7.6 \times 10^{-4 \%}$ for a post assembly environmentally tested wedge bond and $6.5 \times 10^{-6} \%$ for a virgin wedge bond. The fixed-angle pull test can determine the true strength and statistical scattering of the wire bonds better than the loop-hook pull test, and by a careful Weibull statistical analyses, the degradation of bond strength from the post assembly environmental tests can be detected. Further studies are recommended to identify the cause of wedge bond strength degradation during the post assembly environmental tests. 


\section{REFERENCES}

1. F. Ho, "A Modified Welbull Theory for the Strength of Granular Brittle Material", General Atomic Co. GA-Al5228, p. 3,9; May 1979.

2. G. J. Hahn and S. S. Shapiro, "Statistical Models in Engineering", Wiley \& Sons, New York, 1967.

3. H. L. Oh and I. Finnie, "On the Location of Fracture in Brittle Solids-I: Due to Static Loading", J. Fracture Mechanics, 6 (1970); 287-300.

4. W. Nelson, "Theory and Applications of Hazard Plotting for Censored Failure Data", Technometrics, 14 (1972); 945-66.

5. "W79 JTA HMC Wire Pull Test", Letter from J. R. Sim, BX842 Bendix to D. N. Bray, SNLL, 8424, dated May. 1, 1981.

6. "Analysis of JTA HMC (P/N 239376, S/N 1009) Wire Bond Failure", Memo from R. J. Blazek, Bendix to J. R. Williams, August 28, 1981 .

7. "239376 HMC Wire Bond Fallures", Memo from J. B. W1lliams, D/863 Bendix to R. D. Elmore, D/134 BW31, dated September 28, 1981. 
UNLIMITED RELEASE

INITIAL DISTRIBUTION

Bendix Corporation

P. 0. Box 1159

Kansas C1ty, MO 64141

Attn: J. R. Sim, D/842

J. W. Dini, LLNL, L-332

T. B. Cook, 8000; Attn: A. N. Blackwe11, 8200

B. F. Murphey, 8300

L. Gutierrez, 8400

D. L. Hartley, 8500

D. M. 01son, 8100 ; Attn: J. F. Barham, 8110

J. L. Wirth, 8150

D. J. Bohrer, 8111

R. D. Cozine, 8160

W. E; Alzheimer, 8120; Attn: C. S. Hoyle, 8122

W. D. Zinke, 8123

R. J, Gallagher, 8124

G. A. Benedetti, 8121

Y. R. Kan, 8121 (10)

V. C. Prant11, 8121

H. R. Johnson, 8312

M. W. Mote, 8312

J. Cashen, 8329

0. Schrelber, 8329; Attn: C. DeCarli

C. M. Tapp, 8460

R. J. Tockey, 8461; Attn: A. T. Hul1, G. A. Mayer, L. D. Humphreys

D. N. Bray, 8466; Attn: F. Uribe, B. Noble

Publications Division, 8265, for TIC (2)

Publications Division, 8265/Technical Library Processes D1vision, 3141

Technical Library Processes Division, 3141 (3)

M. A. Pound, 8214, for Central Technical Files (3) 


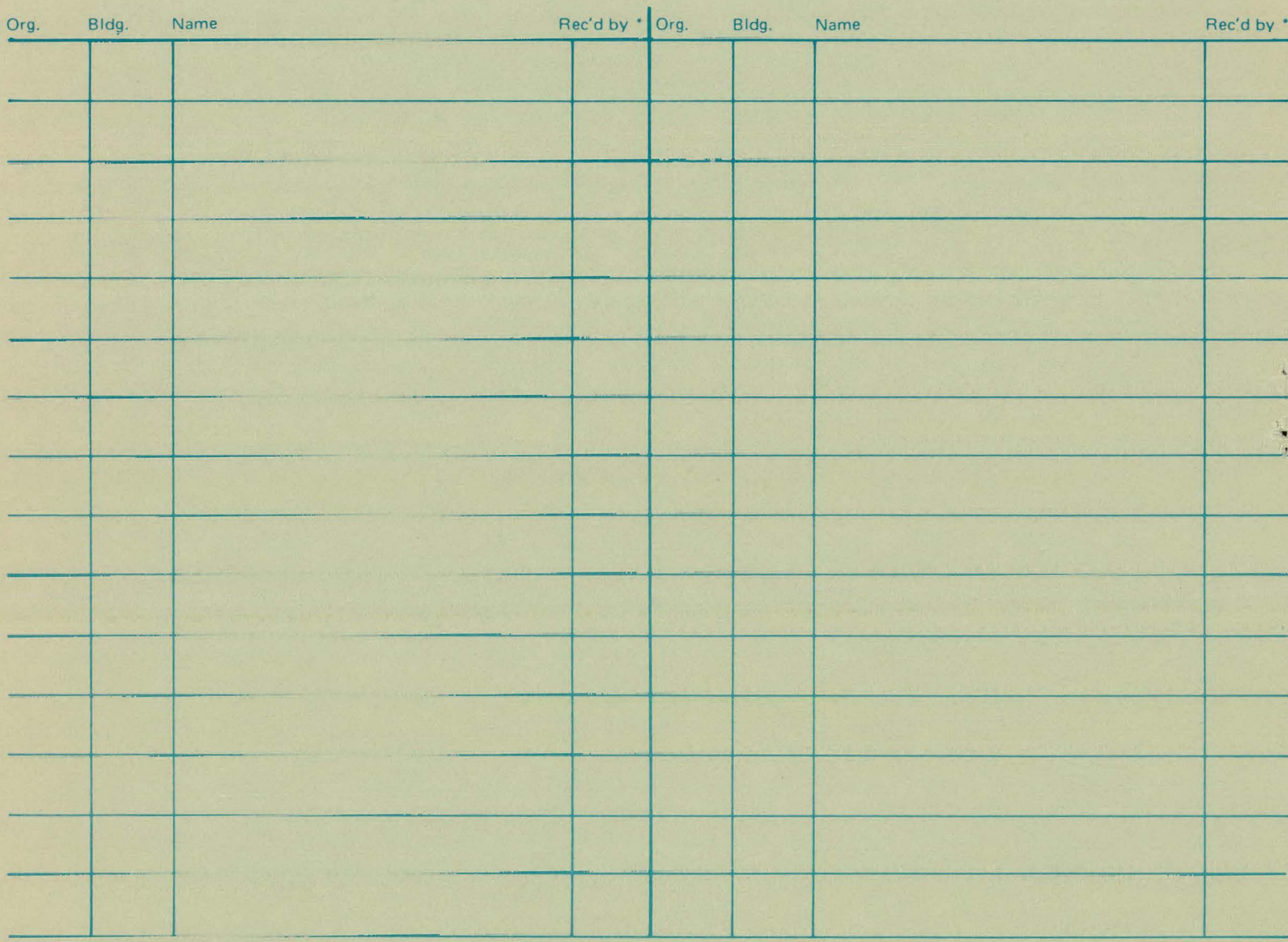

